\title{
A randomised controlled trial of anti-smoking advice:
} 10-year results

\author{
GEOFFREY ROSE, P J S HAMILTON, * L COLWELL, AND M J SHIPLEY \\ From the Department of Medical Statistics and Epidemiology, London School of Hygiene and Tropical \\ Medicine, London, $\mathrm{UK}$
}

SUMMARY Ten-year results are reported from a randomised controlled trial of anti-smoking advice in 1445 male smokers, aged 40-59, at high risk of cardiorespiratory disease. After one year, reported cigarette consumption in the intervention group (714 men) was one-quarter that of the "normal care" group (731 men); over 10 years the nett reported reduction averaged 53\%. The intervention group experienced less nasal obstruction, cough, dyspnoea, and loss of ventilatory function. Over 10 years their mortality from coronary heart disease was $18 \%$ lower than controls (49 and 62 deaths), and that for lung cancer was 23\% lower (18 and 24 deaths). Deaths from non-lung cancers were higher in the intervention group (28v12 deaths). This unexpected difference was due about equally to an excess in intervention and a deficiency in normal care men, it showed no site specificity, and it was unrelated to change in smoking habit. These findings suggest that it is more likely to have been due to chance than to intervention. The total number of deaths were 123 in the intervention group and 128 in normal care (95\% confidence limits of difference $-22 \%$ to $+23 \%)$. The policy of encouraging smokers to give up the habit should not be changed.

The health of ex-smokers and continuing smokers has been compared in many observational studies; but the results are not easy to interpret, since ex-smokers are not a random selection of former smokers. Their history of smoking tends to differ, not only in the amount smoked (which can be allowed for) but also in inhalation and choice of brand; and subtle interactions between these factors make it difficult to allow for their effects. ${ }^{1}$ They may differ moreover in other sorts of health-related behaviour, as well as in social class and environment and in preceding levels of risk factors. ${ }^{2}$ Furthermore, the decision to stop smoking may have been prompted by ill health, and this would leave ex-smokers with an impaired prognosis. For all these reasons the lower mortality of ex-smokers observed in most studies does not simply reflect the effect of stopping smoking. Only a randomised controlled trial of stopping smoking can offer an unbiased comparison.

In 1968 we set up such a trial as part of the Whitehall Study. ${ }^{3}$ Preliminary results have been reported. 'At that time, after an average of 7.9 years' follow-up, deaths were too few to warrant

-Present address: PAHO/WHO Caribbean Epidemiology Center, PO Box 164, Port of Spain, Trinidad. presentation of cause-specific mortality. We now present a report based on 10 years of follow-up and 251 deaths.

\section{Subjects and methods}

Details were given in the previous report. ${ }^{4}$ In 1968-70 we screened 16016 men aged 40 to 59 during the Whitehall Study of London civil servants. The results, which were first sent to general practitioners, were used to select 1445 cigarette smokers with the highest risk of coronary heart disease or chronic bronchitis, or both, based on a multivariate combination of risk factor levels. These men were divided randomly into two groups. Those in the "intervention" group (714 men) were recalled for individual advice on the relation of smoking to their health, and they were challenged to consider their situation. Those (the large majority) who declared a wish to stop smoking were given support and encouragement, continuing on average for four further visits over the ensuing 12 months. No other health advice was given, except on calorie restriction for those who gained weight.

The remaining 731 men served as a "normal care" control group. They were not recalled or advised by 
us, but full reports on their examination findings were sent to their general practitioners. This seldom led to any advice on smoking. The two groups were initially well matched (table 1).

After one year in the trial, and again after three years, men in both the intervention and normal care groups received a self-administered questionnaire on current smoking habits, symptoms and recent illnesses, together with an appointment for a physical examination. A further postal inquiry about smoking habits was undertaken after men had been in the trial for about nine years. The records of all participants were "flagged" at the National Health Service Central Registry, which provided coded copies of all death certificates and (for the period 1971-9) of cancer registrations. In deaths ascribed to cancer we wrote to the hospital doctors, seeking details of histological verification. The present report analyses 10 years' experience of mortality and notified incidence of cancer.

\section{Results}

CHANGES IN SMOKING HABIT

The questionnaire response rates among survivors were $84 \%$ at one year, $70 \%$ at three years, and $83 \%$ at nine. Losses were mainly in retired men. In the intervention group the proportion of responders who said that they were not smoking any cigarettes was $63 \%$ at one year, $57 \%$ at three years, and $55 \%$ at nine.

Table 1 Initial characteristics of the two groups

\begin{tabular}{lcc}
\hline & Normal care & Intervention \\
\hline No of men & 731 & 714 \\
Mean age (years) & 53.0 & 52.8 \\
Mean cigarettes/day & 18.9 & 19.1 \\
Winter morning phlegm (\%) & 59 & 54 \\
ECG: suspected ischaemia (\%) & 10 & 9 \\
Mean body weight (kg) & 74.6 & 74.6 \\
\hline
\end{tabular}

About a third of those giving up cigarettes continued to smoke a pipe or cigars. The figure shows the trends in stated numbers of cigarettes smoked. At entry to the trial consumption fell dramatically in the intervention group, and after a year it was one-quarter of the normal care level. Thereafter it tended to rise a little, whereas that of normal care men slowly fell. By nine years the estimate for intervention men was $70 \%$ of that for controls. Over the 10 years the nett apparent reduction in the intervention group averaged $\mathbf{7 . 6}$ cigarettes/day $(-53 \%)$ compared with the control level.

\section{CHANGES IN SYMPTOMS AND PHYSICAL FINDINGS}

Changes were assessed after one and three years. Men in the intervention group reported a large fall in the prevalence of nasal obstruction, cough, phlegm, and dyspnoea. Blood pressure did not change significantly, and weight rose by an average of $2 \mathrm{~kg}$. The rate of decline of ventilatory function was slower than in control men. Fuller information, including sickness absence rates, is given in the earlier report.

\section{MORTALITY}

During the 10 years of follow-up there were 251 deaths compared with 257 deaths expected from the age-specific rates for England and Wales in 1974. The fact that all men entering the trial were high-risk smokers should have increased the expected deaths, but this may have been offset by the "healthy worker" effect in an occupational study group. Deaths were also close to national levels for coronary heart disease (111 observed, 94 expected), lung cancer (42 observed, 35 expected) and other cancers (40 observed, 41 expected). Seventy-two per cent of deaths occurred in hospital, and in $45 \%$ there was a necropsy. Causes were coded according to the 8th revision of the International Classification of Diseases. The results are summarised in table 2 ,

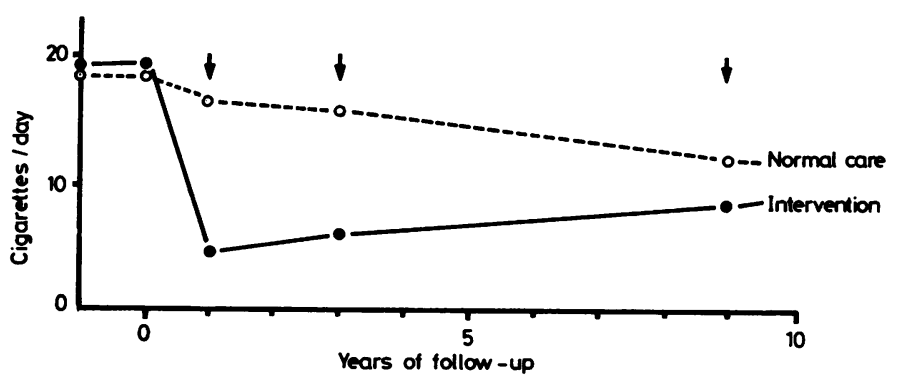

Mean daily cigarette consumption reported by normal care and intervention groups at initial survey, and entry to trial, one-year and three-year re-examinations, and final postal inquiry. 
Table 2 Life-table probabilities \% (and standard errors) of death, or death plus cancer registration, in normal care (NC) and intervention (I) groups

\begin{tabular}{|c|c|c|c|c|c|c|c|c|c|}
\hline \multirow{3}{*}{$\begin{array}{l}\text { Years } \\
\text { in trial }\end{array}$} & \multirow{3}{*}{$\begin{array}{c}\text { Group } \\
\text { NC }\end{array}$} & $\begin{array}{l}\text { Coronary } \\
\text { heart disease }\end{array}$ & $\begin{array}{l}\text { Lung cancer (including } \\
\text { registrations) }\end{array}$ & \multicolumn{2}{|c|}{$\begin{array}{l}\text { Other cancers (including } \\
\text { registrations) }\end{array}$} & \multicolumn{2}{|c|}{$\begin{array}{l}\text { Deaths other than } \\
\text { cancer or } \\
\text { cardiovascular }\end{array}$} & \multicolumn{2}{|c|}{$\begin{array}{l}\text { All causes } \\
\text { of death }\end{array}$} \\
\hline & & $1.1 \quad(0.39)$ & $0.7 \quad(0.31)$ & 0.3 & $(0 \cdot 19)$ & 0.0 & (一) & 1.6 & $(0.47)$ \\
\hline & & $0.6 \quad(0.28)$ & $0.7 \quad(0.31)$ & 0.9 & $(0.35)$ & 0.1 & $(0 \cdot 14)$ & $2 \cdot 4$ & $(0.57)$ \\
\hline 4 & NC & $2.5 \quad(0.58)$ & $1.0 \quad(0.36)$ & 0.8 & $(0.34)$ & 0.6 & $(0.28)$ & $4 \cdot 7$ & $(0.78)$ \\
\hline & I & $2.2 \quad(0.55)$ & $1.4(0.45)$ & 2.6 & $(0.60)$ & 0.4 & $(0.25)$ & 5.9 & $(0.88)$ \\
\hline 6 & NC & $4.0 \quad(0.73)$ & $2.1 \quad(0.54)$ & 1.4 & $(0.44)$ & 0.9 & $(0.35)$ & $7 \cdot 8$ & $(0.99)$ \\
\hline & I & $3.2 \quad(0.67)$ & $2.0 \quad(0.54)$ & $4 \cdot 2$ & $(0.77)$ & $1 \cdot 0$ & $(0.39)$ & $8 \cdot 7$ & $(1.05)$ \\
\hline 8 & NC & $6.1 \quad(0.90)$ & $3.5 \quad(0.69)$ & $2 \cdot 3$ & $(0.57)$ & 1.5 & $(0.46)$ & $12 \cdot 2$ & $(1.21)$ \\
\hline & 1 & $5.3 \quad(0.86)$ & $2.5 \quad(0.60)$ & $5 \cdot 3$ & $(0.86)$ & 1.4 & $(0.45)$ & $12 \cdot 7$ & $(1.25)$ \\
\hline 10 & NC & $8.9 \quad(1.08)$ & $3.6(0.71)$ & $2 \cdot 8$ & $(0.63)$ & $2 \cdot 7$ & $(0.64)$ & $17 \cdot 5$ & $(1.41)$ \\
\hline & I & $7.3 \quad(1.00)$ & $3.3 \quad(0.70)$ & $6 \cdot 1$ & $(0.92)$ & 1.9 & $(0.53)$ & $17 \cdot 2$ & $(1.41)$ \\
\hline Total No & NC & $\begin{array}{l}(62) \\
(49)\end{array}$ & (25) & (19) & & (18) & & (128) & \\
\hline
\end{tabular}

Table 3 Smoking status at one year related to 10-year mortality from lung and other cancers

\begin{tabular}{|c|c|c|c|c|c|c|c|c|c|c|c|c|c|c|c|}
\hline \multirow[b]{2}{*}{ Status at one year } & \multicolumn{3}{|c|}{ No of men } & \multicolumn{6}{|c|}{$\begin{array}{l}\text { No (\%) dying of } \\
\text { lung cancer }\end{array}$} & \multicolumn{6}{|c|}{$\begin{array}{l}\text { No }(\%) \text { dying of } \\
\text { other cancers }\end{array}$} \\
\hline & $N C$ & $I$ & Total & $N C$ & & $I$ & & Tot & & $N$ & & $I$ & & Tot & \\
\hline $\begin{array}{l}\text { Smoking cigarettes } \\
\text { Stopped cigarettes } \\
\text { Complete non-smoker } \\
\text { Smoking pipe/cigars } \\
\text { Dead or not known }\end{array}$ & $\begin{array}{r}552 \\
75 \\
56 \\
19 \\
104\end{array}$ & $\begin{array}{l}215 \\
363 \\
227 \\
136 \\
136\end{array}$ & $\begin{array}{l}767 \\
438 \\
283 \\
155 \\
240\end{array}$ & $\begin{array}{r}16 \\
1 \\
1 \\
0 \\
7\end{array}$ & $\begin{array}{l}\% \\
(2 \cdot 9) \\
(1 \cdot 3) \\
(1 \cdot 8) \\
(-) \\
(6 \cdot 7)\end{array}$ & $\begin{array}{l}5 \\
6 \\
3 \\
3 \\
7\end{array}$ & $\begin{array}{l}\% \\
(2 \cdot 3) \\
(1 \cdot 7) \\
(1 \cdot 3) \\
(2 \cdot 2) \\
(5 \cdot 1)\end{array}$ & $\begin{array}{r}21 \\
7 \\
4 \\
3 \\
14\end{array}$ & $\begin{array}{l}\% \\
(2 \cdot 7) \\
(1 \cdot 6) \\
(1 \cdot 4) \\
(1 \cdot 9) \\
(5 \cdot 8)\end{array}$ & $\begin{array}{l}6 \\
1 \\
0 \\
1 \\
5\end{array}$ & $\begin{array}{l}\% \\
(1 \cdot 1) \\
(1 \cdot 3) \\
(-) \\
(5 \cdot 3) \\
(4 \cdot 8)\end{array}$ & $\begin{array}{r}8 \\
13 \\
7 \\
6 \\
7\end{array}$ & $\begin{array}{l}\% \\
(3 \cdot 7) \\
(3 \cdot 6) \\
(3 \cdot 1) \\
(4 \cdot 4) \\
(5 \cdot 1)\end{array}$ & $\begin{array}{r}14 \\
14 \\
7 \\
7 \\
12\end{array}$ & $\begin{array}{l}\% \\
(1 \cdot 8) \\
(3 \cdot 2) \\
(2 \cdot 5) \\
(4 \cdot 5) \\
(5 \cdot 0)\end{array}$ \\
\hline
\end{tabular}

NC = Normal care.

I = Intervention group.

which also includes additional data from the National Cancer Register on cases histologically confirmed either by biopsy or at necropsy in deaths from other causes.

\section{Coronary heart disease (ICD 410-14)}

The 10-year life table probability of death was $8.9 \%$ for the normal care group (62 deaths) and 7.3\% (49 deaths) for the intervention group, a proportionate change of $-18 \%(95 \%$ confidence limits -43 to $+18 \%)$. Among the 369 men who entered the trial with evidence of myocardial ischaemia (angina, history of possible infarction, or positive electrocardiogram) the reduction was $-23 \%$, compared with $-11 \%$ in those without such evidence. Deaths from cardiovascular causes other than coronary heart disease were 12 in the normal care group (including five from stroke), and 13 in the intervention group (including seven from stroke).

\section{Lung cancer (ICD 162.1)}

Deaths from lung cancer and other lung cancer registrations numbered 24 and one respectively in the normal care group, and 18 and four respectively in the intervention group. Thus the estimated proportionate reduction in 10-year risk was -23\% for deaths $(95 \% \mathrm{cl}-58$ to $+41 \%)$, and $-8 \%$ for deaths plus registrations $(95 \% \mathrm{cl}-48$ to $+61 \%)$. It will be seen that the confidence intervals are wide. Histological proof of the diagnosis (biopsy or necropsy) was available in $21(88 \%)$ of the normal care cases and $14(78 \%)$ of those in the intervention group. In the normal care cases where we had details there were 10 with squamous-cell cancer, in contrast with only one out of eight in the intervention group.

\section{Cancers at all other sites}

Cancer at all other sites showed overall a large excess in the intervention group throughout the trial. For mortality the gap was widest at eight years, when there had been six such deaths in normal care and 23 in intervention subjects. At 10 . years deaths numbered 12 and 28 respectively $(p=0.01$-see discussion). Registrations of other cases during the 10-year period were seven in the normal care and 13 in the intervention group, giving totals for deaths plus registrations of 19 and 41 respectively $(p=0.003)$. Among the deaths the diagnosis was histologically proved in nine $(75 \%)$ of the normal care cases and 22 (79\%) of the intervention cases.

During a further period of incomplete follow-up of up to three years, there have been four more deaths from non-lung cancers in the normal care and seven in the intervention group, two of whom were previously registered cases. 
Table 3 relates the cancer death rates to smoking status after one year in the trial. Lung cancer mortality is lower in those who gave up cigarettes, to an approximately similar extent in each group. For non-lung cancers the excess in the intervention group is as great in continuing smokers as in ex-smokers. The 155 men who stopped cigarettes but continued with pipe or cigars have slightly higher mortality from lung and other cancers. Their experience, however, accounts for only a little of the intervention group's excess of non-lung cancers: if they are removed the incidence for the normal care group becomes 18/712 (2.5\%) compared with $35 / 578(6 \cdot 1 \%)$ for the intervention group.

Table 4 compares the observed numbers of deaths from cancer with those expected on the basis of national (England and Wales) age-specific rates in 1974. For all sites combined the normal care group was $8 \%$ below expectation while the intervention group was $24 \%$ above it. The normal care group was, however, high for lung cancer (as would be expected, since initially all were smokers and most continued to be so). The absence of an excess of lung cancer in intervention subjects was commensurate with their reduced smoking. The difference between the two groups in respect of other cancers is seen to be due in about equal measure to a deficiency of deaths in normal care men and an excess in the intervention group: each of these differences fell just short of the $5 \%$ level of significance. This overall statement holds good also for site-specific analysis: in each instance the number of intervention deaths is above expectation and (except for the one death from bone cancer) that of the normal care group is below expectation. When cancer sites are grouped according to whether or not they are recognised as having a special smoking-related risk there is again no suggestion that the difference between normal care and intervention groups arises from any particular category. In summary, the distribution of non-lung cancer cases by site is not remarkable in either group of the trial, but the general level is below expectation in one group and above expectation in the other.

\section{Deaths from other causes}

Deaths from other causes occurred in 18 normal care and 12 intervention subjects. More detailed analysis was uninformative.

\section{All-causes mortality}

All causes mortality was initially higher (though not significantly so) in the intervention group, but during the last six years of the trial the rates were higher in the normal care group. During the whole 10 years 123 intervention men $(17 \cdot 2 \%)$ died compared with $128(17.5 \%)$ of the normal care group-a proportionate change of $-2 \%(95 \%$ cl $-22 \%$ to $+23 \%)$.

For deaths other than those from non-lung cancers there is a progressive advantage to the intervention group, amounting after 10 years to a proportionate fall of $-16 \%$ (116 normal care $v 95$ intervention group deaths).

Causes of death were also grouped according to whether or not they are smoking-related.* There were 92 such deaths in the normal care group and 81 in the intervention, a proportionate change of $-9 \%$ $(95 \% \mathrm{cl}-31 \%$ to $+20 \%)$.

\section{Discussion}

The causal role of cigarette smoking in coronary heart disease, lung cancer, and chronic bronchitis and emphysema is widely accepted. For the respiratory diseases this explanation probably accounts for nearly all of their observed association with smoking; but for coronary heart disease this is less certain, especially in older people. Thus life-long avoidance

-That is, coronary heart disease (ICD 410-4), chronic bronchitis (491), and cancers of the respiratory tract $(140,143-9)$, oesophagus (150), urinary tract (188-9) and pancreas (157).

Table 4 Comparison by site ofobserved deaths from cancer with those expected from rates for men of same ages in England and Wales, 1974

\begin{tabular}{|c|c|c|c|c|c|c|}
\hline & \multicolumn{3}{|c|}{ Normal care } & \multicolumn{3}{|c|}{ Intervention } \\
\hline & Obs & $\operatorname{Exp}$ & Ratio & Obs & $\operatorname{Exp}$ & Ratio \\
\hline All sites & 36 & 38.9 & 0.92 & 46 & $37 \cdot 1$ & $1 \cdot 24$ \\
\hline Lung & 24 & $18 \cdot 1$ & $1 \cdot 3$ & 18 & $17 \cdot 2$ & $1 \cdot 0$ \\
\hline All other sites & 12 & $20 \cdot 8$ & 0.58 & 28 & 19.9 & 1.41 \\
\hline Other respiratory & $\mathbf{0}$ & 0.6 & 0 & 2 & 0.6 & $3 \cdot 3$ \\
\hline Digestive & 5 & $11 \cdot 2$ & 0.4 & 13 & 10.6 & $1 \cdot 2$ \\
\hline Genitourinary & 2 & $3 \cdot 1$ & 0.6 & 4 & $2 \cdot 9$ & 1.4 \\
\hline Lymphatic & 0 & $2 \cdot 0$ & 0 & 3 & $2 \cdot 0$ & $1 \cdot 5$ \\
\hline Bone & 1 & $0 \cdot 1$ & 10 & 1 & 0.1 & 10 \\
\hline Other unspecified & 4 & $3 \cdot 8$ & $1 \cdot 0$ & 5 & $3 \cdot 7$ & 1.4 \\
\hline All smoking-related sites* & 26 & $24 \cdot 0$ & $1 \cdot 1$ & 29 & $22 \cdot 8$ & $1 \cdot 3$ \\
\hline All other sites & 10 & $14 \cdot 9$ & 0.7 & 17 & $14 \cdot 3$ & $1 \cdot 2$ \\
\hline
\end{tabular}

-Defined in text. 
of cigarettes can be expected to reduce the risk of each of these conditions to an extent ranging from near-complete avoidance of lung cancer down to a smaller and less certainly definable reduction in coronary heart disease.

The cigarette-induced damage that may culminate in disability and death is the outcome of many years of exposure, accompanied by progressive pathological changes that are not necessarily reversible. Studies that have compared continuing and ex-smokers have nevertheless nearly all observed a large apparent advantage to the latter ${ }^{5-8}$; but such comparisons could be biased by the differences, both known and unknown, between those in the population who choose to continue smoking and those who choose to stop. This objection does not apply to the observed fall in mortality from smoking-related causes among British doctors as a whole, over a period in which their smoking greatly declined ${ }^{7}$, but it is possible that other factors may have contributed. Only a randomised trial offers a direct test of the reversibility of the risks from smoking. Such a trial presents formidable difficulties, and unfortunately the present report seems likely to stand as the only such single-factor randomised controlled study. Less direct evidence may come from some of the current multifactor intervention trials. Incidence results from the UK heart disease prevention project ${ }^{\ominus}$ do not suggest any excess of cancer risk among the 9734 men in the intervention group; and in the Oslo trial ${ }^{10}$ there were five deaths from cancer in the intervention group compared with eight in controls.

The trial was designed to test whether the total reduction in cardiorespiratory disease among middle-aged men was as large as that indicated by the observational studies of ex-smokers. Its size was planned in the expectation that incidence as well as mortality data would be available; when this proved unattainable, the loss of power was partly offset by extending the mortality follow-up to 10 years. A larger trial would have been better; but the screening of over 16000 men, and repeated personal interviews with over 700 of them, stretched our resources to the limit.

The reduction in smoking among intervention subjects was a little better than expected, with almost two-thirds of those attending the one-year follow-up examination claiming to have given up cigarettes altogether, and most of the others claiming to be smoking much less than before. Objective tests of smoking behaviour were not available to us at that time. No doubt there was exaggeration of claims to have cut down, but we thought that those reporting complete cessation were generally truthful. The reports were based on questionnaires completed at home, with little external pressure; and they were largely consistent over the ensuing years, the progressively narrowing gap between the two groups being due mainly to a gradual reduction in smoking by normal care men. Thus although the size of the gap may have been overestimated, there is no doubt that throughout the earlier years of the trial it was large.

If the trial had been started a few years later we should have done more to discourage pipe and cigar smoking by intervention subjects, since it now seems that in former cigarette smokers this may often be associated with continued inhalation. The continuing pipe and cigar smokers are not a randomly chosen group, but in general their risks for both cardiovascular and respiratory causes of death did not seem to be much different from those who gave up smoking entirely.

Over the trial as a whole the intervention group's level of smoking exposure was estimated as about half that of the normal care group, implying that the best estimates of the effects of complete cessation might be about double those observed in the trial. For coronary heart disease mortality the latter was $-18 \%$, which is in fact the same as was observed in the first 10 years follow-up of the British doctors study. ${ }^{11}$ The pattern observed in the trial suggested a gradually accumulating benefit, and in this respect it supports the large longitudinal surveys rather than the apparently immediate benefit reported among survivors of myocardial infarction, ${ }^{12-14}$ or, based on small numbers, by the Framingham study. ${ }^{15}$

Lung cancer mortality was $23 \%$ lower in the intervention group, but this estimate of benefit fell to $8 \%$ if other registered cases were included. (Most of the latter are dead from various causes other than lung cancer, and therefore appear in the total for all deaths.) Again, allowing for non-adherence, either of these estimates is within sampling limits of the prediction based on observational studies.

As set out in our previous report," respiratory morbidity was considerably improved by stopping smoking. The commonest benefit, much appreciated by the men but curiously overlooked in previous reports, was a reduction in nasal obstruction. There were also the expected improvements in bronchitic symptoms, and a slowing in the rate of loss of ventilatory function. Deaths from bronchitis and emphysema were too few to asssess (four in normal care and four in intervention men).

When the trial was planned the only possible adverse effect envisaged was psychological (which proved to be only minor). It came as a surprise to observe an adverse trend among deaths from those causes that we did not expect to influence; and this excess, in absolute terms, tended to widen. It turned out to be due to the mortality from non-lung cancers 
being nearly $140 \%$ higher in the intervention than the normal care group $(p=0.01)$, with a similar trend for other registered cancers. The total difference for "deaths plus other registrations" was remarkable (19 $v 41$ cases, $\mathrm{p}=0.003$ ) and disturbing. It is unlikely to be due to biased ascertainment: the clinicians who completed the death certificates were generally unaware of the trial's existence, and the proportions with histological proof were high and almost the same in the two groups-75\% (normal care) and 79\% (intervention) for deaths, and effectively $100 \%$ for other registered cases. There are, nevertheless, some cogent arguments for attributing it to chance.

(1) The hypothesis only emerged from inspection of the results at the end of the first five years: this particular grouping of end-points was then identified from among an unknown number, any one of which might have been analysed and reported had it appeared remarkable. The significance estimates are undoubtedly too extreme, but to an unknown extent.

(2) As judged by national experience, the difference between the groups was due as much to a deficiency of control cases as to an excess in the intervention men. The former as much as the latter calls for an explanation.

(3) The distribution of cancers by site was as expected in both groups, the difference showing no specificity for particular sites; in particular, it was not concentrated among sites recognised as being related to smoking (nor vice versa).

(4) The excess in the intervention group was not concentrated among the men who stopped smoking cigarettes, nor among those who (perhaps as a result of our discouragement of cigarettes) smoked a pipe or cigars. It was a characteristic of the intervention group as a whole rather than of acceptance of anti-smoking advice.

(5) No general excess of such deaths from cancer has been reported in major observational studies of ex-smokers (table 5).

These arguments favour the view that the finding is due to chance, rather than that the advice given caused an increase in mortality from cancers at various sites. The latter possibility must nevertheless be considered, and there are some arguments in its favour.

(1) Even allowing for the a posteriori hypothesis, chance would not often produce a difference as large as this.

(2) The trial was instituted on the argument that the results of a designed experiment should carry special weight, and its findings therefore cannot be lightly dismissed. Moreover the experience of observational studies (negative in respect of a cancer risk) may not be a proper analogy: in the trial the subjects who stopped smoking were selected by doctors and then subjected to particular pressure, whereas those in the general population who give up smoking are mostly self-selected and they act at a time and in a manner of their choosing. Both the people and the experience are different.

(3) In general, particular cancers in man seem to have particular causes; but the possibility of a non-specific enhancement of susceptibility cannot be entirely dismissed.

After much thought, and exhaustive analysis of the data, we think the difference in non-lung cancer mortality and incidence in this trial is more likely to be due to chance than to an effect of intervention. Such evidence as there is for the latter view should be considered as a hypothesis for further study, not as the basis for conclusions or for any recommendation to smokers. Even if the effect were real (which we doubt) the evidence would imply that it came, not from giving up cigarettes, but from some other and unidentified result of intervention.

Results for total mortality represented the approximate balance of a favourable trend for smoking-related diseases and the adverse trend for non-lung cancers. Deaths other than those from non-lung cancers totalled 116 (normal care) and 95 (intervention), a reduction in rate of $16 \%$. Correcting for the dilution effect from those who continued smoking, this gives a best estimate of an approximately

Table 5 Mortality rates according to smoking status in men aged 45-64 (standardised to the age structure of the Whitehall Study), as reported from the Dorn study of US Veterans' the first 10 years' follow-up of the British doctors study, ${ }^{11}$ and the 10-year follow-up of the Whitehall Study (unpublished)

\begin{tabular}{|c|c|c|c|c|}
\hline Cause of death & Cigarette smoking status & Kahn** & $\begin{array}{l}\text { Deaths } / 100000 / y \\
\text { Doll and Hill' }\end{array}$ & Whitehall \\
\hline All causes & $\begin{array}{l}\text { Non- } \\
\text { Ex- } \\
\text { Present }\end{array}$ & $\begin{array}{r}710 \\
1011 \\
1460\end{array}$ & $\begin{array}{r}788 \\
1071 \\
1353\end{array}$ & $\begin{array}{r}484 \\
611\end{array}$ \\
\hline All cancers & $\begin{array}{l}\text { Non- } \\
\text { Ex- } \\
\text { Present }\end{array}$ & $\begin{array}{l}136 \\
227 \\
320\end{array}$ & $\begin{array}{l}106 \\
132 \\
297\end{array}$ & $\begin{array}{l}147 \\
191 \\
374\end{array}$ \\
\hline Non-lung cancers & $\begin{array}{l}\text { Non- } \\
\text { Ex- } \\
\text { Present }\end{array}$ & $\begin{array}{l}130 \\
181 \\
215\end{array}$ & $\begin{array}{l}106 \\
104 \\
172\end{array}$ & $\begin{array}{l}129 \\
142 \\
213\end{array}$ \\
\hline
\end{tabular}

"Excludes ex-smokers giving up on medical advice. 
$30 \%$ reduction in mortality from stopping smoking among these men, excluding any effect of intervention on non-lung cancers.

In our view the present policy of encouraging smokers to give up the habit should not be changed: stopping smoking benefits respiratory symptoms and cardiorespiratory disability, and it appears to reduce the risks of death from lung cancer and coronary heart disease. Other possible effects should be the subject of further research.

We thank the Civil Service Medical Department; the subjects, who gave such excellent co-operation; Miss J K Pateman SRN, Miss P Gilford, SRN, and Mrs J Thiedeman.

Reprints from Professor Geoffrey Rose, London School of Hygiene and Tropical Medicine, Keppel Street, London WC1E 7HT.

\section{References}

${ }^{1}$ Higenbottam T, Shipley M, Rose G. Cigarettes, lung cancer, and coronary heart disease: the effects of inhalation and tar yield. J Epidemiol Community Health 1982; 36: 113-7.

${ }^{2}$ Friedman GD, Siegelaub AB, Dales LG, Seltzer CC. Characteristics predictive of coronary heart disease in ex-smokers before they stopped smoking: comparison with persistent smokers and non-smokers. J Chron Dis 1979; 32: 175-90.

${ }^{3}$ Reid DD, Brett GZ, Hamilton PJS, Jarrett RJ, Keen H, Rose G. Cardiorespiratory disease and diabetes among middle-aged male civil servants. Lancet 1974; i: 469-73.
${ }^{4}$ Rose G, Hamilton PJS. A randomised controlled trial of the effect on middle-aged men of advice to stop smoking. J Epidemiol Community Health 1978; 32: 275-81.

${ }^{5}$ Hammond EC. Smoking in relation to one million men and women. Natl Cancer Inst Monogr 1966; 19: 127-204.

${ }^{6} \mathrm{Kahn}$ HA. The Dorn study of smoking and mortality among US veterans: report on eight and one-half years of observation. Natl Cancer Inst Monogr 1966; 19: $1-125$.

'Doll R, Peto R. Mortality in relation to smoking: 20 years' observations on male British doctors. $\mathrm{Br}$ Med J 1976; ii: 1525-36.

${ }^{8}$ Reid DD, Hamilton PJS, McCartney P, Rose G, Jarrett RJ, Keen H. Smoking and other risk factors for coronary heart disease in British civil servants. Lancet 1976; ii: 979-84.

${ }^{9}$ Rose G, Heller RF, Tunstall Pedoe HD, Christie DGS. Heart disease prevention project: a randomised controlled trial in industry. $\mathrm{Br}$ Med J 1980; 280: 747-51.

${ }^{10}$ Hjermann I, Byre KV, Holme I, Leren P. Effect of diet and smoking intervention on the incidence of coronary heart disease. Lancet 1981; ii: 1304-10.

${ }^{11}$ Doll $\mathrm{R}$, Hill AB. Mortality in relation to smoking: ten years' observations of British doctors. Br Med J 1964; i: 1399-1410, 1460-7.

${ }^{12}$ Wilhelmsson D, Vedin JA, Elmfedt D, Tibblin G, Wilhelmsen $\mathbf{L}$. Smoking and myocardial infarction. Lancet 1975; i: 415-20.

${ }^{13}$ Mulcahy R, Hickey N, Graham I, Macairt J. Factors affecting the five-year survival rate of men following acute coronary heart disease. Am Heart J 1977; 93: 556-9.

${ }^{14}$ Salonen JT. Stopping smoking and long-term mortality after acute myocardial infarction. Br Heart J 1980; 43: 463-9.

${ }^{15}$ Gordon R, Kannel WB, McGee D, Dawber TR. Death and coronary attacks in men after giving up cigarette smoking. Lancet 1974; ii: 1345-8. 